\title{
Effects of Formation Brine Compositions on Effectiveness of Low Salinity Brine Injection in Carbonate Reservoir
}

\author{
Suthida Meekangwal \\ Department of Mining and Petroleum Engineering \\ Faculty of Engineering, Chulalongkorn University \\ Bangkok, Thailand \\ Suthida.me@student.chula.ac.th
}

\author{
Falan Srisuriyachai \\ Department of Mining and Petroleum Engineering \\ Faculty of Engineering, Chulalongkorn University \\ Bangkok, Thailand \\ Falan.s@chula.ac.th
}

\begin{abstract}
Nowadays, Low Salinity Waterflooding (LSWF) is considered as one of the most effective techniques to enhance oil recovery. Essential mechanism is a Multi-Ion Exchange (MIE). In carbonate formation, collaboration of Potential Determining Ions (PDI) with rock surface and crude oil results in adjustment of surface equilibrium. These ions in injected brine are thoroughly investigated but effects from formation brine are not well documented. In this study, ratio of divalent ions including calcium and magnesium ions in formation brine is studied. Results from imbibition test shows that formation brine containing calcium ion to magnesium ion ratio of $1: 1$ yields response to LSWF. Oppositely, formation brines with high ratios of 10:1 and 15:1 do not respond to LSWF. As calcium ion in connate water diffuses to injected water, high calcium ion will exhibit dissolution mechanism of rock surface which is part of oil recovery mechanisms. Formation brine with high calcium ion is therefore not recommended for LSWF. High portion of magnesium ion in formation brine does not affect effectiveness of LSWF. Dissolution of magnesium from rock may be obstructed but oil can still be liberated from calcium carboxylate complex and dissolution of calcium. Coreflood test shows similar result which confirms previous explanation.
\end{abstract}

Keywords-Enhanced oil recovery; low salinity water flooding; Carbonate reservoir; Multi-ion exchange mechanism

\section{INTRODUCTION}

Oil production can be generally performed by means of three recovery methods consisting of primary, secondary, and tertiary recoveries. During the phase of primary recovery, oil is produced by means of natural forces stored inside the reservoir, whereas in secondary recovery, conventional waterfooding and immiscible gas injection are performed to maintain reservoir pressure in order to prolong the production time. Nevertheless, most reservoirs have been foreseen to encounter difficulties of recovering oil by means of previously mentioned techniques. Thus, tertiary recovery is usually selected to perform in order to obtain extension of oil production. This recovery technique is implemented by injecting substances which are absent in the reservoir to generate oil recovery mechanisms beyond pressure maintenance or physical displacement process. In the past decades, waterflooding has been considered as one of the most effective methods for improving oil recovery due to availability of water as well as low investment cost and it is also environmental concerned process. Moreover, reservoirs containing moderate to light crude oil also exhibit positive results due to favorability of mobility ratio. However, complexity of water-oil-rock system sometimes causes waterflooding unable to exhibit the maximum capacity of oil production until residual oil saturation is achieved. This indicates that the extension beyond waterflooding is necessary. In recent years, one of the most attractive modified techniques of waterflooding so-called Low Salinity Waterflooding (LSWF) is investigated. This technique has been proven to recover more oil compared to conventional high salinity waterflooding. Furthermore, LSWF is a low cost technique since low salinity water could be prepared using seawater or fresh water mixed with formation brine without any additional chemical which can be harmful to subsurface environment.

Principally, LSWF is performed by injecting water containing low salinity or low ionic strength compared to that of formation water to create interaction onto rock surface. The cooperation between rock surface, crude oil, and injected low salinity water yields new surface equilibrium and hence; wetting condition is shifted toward a more favorable condition for oil production. LSWF is numerously studied in sandstone reservoirs and many studies have shown satisfactory. Several oil recovery mechanisms for sandstone reservoir were suggested such as fine migration, increase of $\mathrm{pH}$ and in-situ saponification, MultiIon Exchange (MIE), mineral dissolution, and Double Layer Expansion (DLE).

Nevertheless, carbonate reservoirs which contribute more than half of the world's oil reserves, have been rarely investigated for application of LSWF. From current studies, wettability alteration of carbonate rock surface is the most significant mechanism occurred during LSWF. Wettability can be changed due to a presence of potential wettability modifiers comprising sulfate ion $\left(\mathrm{SO}_{4}{ }^{2-}\right)$, calcium ion $\left(\mathrm{Ca}^{2+}\right)$ 
and magnesium ion $\left(\mathrm{Mg}^{2+}\right)$ which are necessary factors for the occurrence of Multi-ion Exchange (MIE). This mechanism results in a more water-wet surface which is favorable condition for oil production. Nevertheless, most studies of LSWF in carbonate reservoir only focus on compositions of injected brine as a major cause of wettability alteration.

As part of surface system, formation water should be thoroughly investigated since it could control several mechanisms and it could be essential factor affecting the efficiency of LSWF as wettability alteration is a mechanism related to rock surface, injected brine, formation brine and crude oil. In this study, different ratios of divalent ions (calcium and magnesium ion) of synthetic formation brine are studied in carbonate rock by means of imbibition test and coreflood test to assess the impact of these Potential Determining Ions (PDI) for carbonate formations. Understanding effects of divalent ions in formation brine will be useful as it can screen candidate carbonate reservoirs that have high potentiality for LSWF technique.

\section{THEORY}

Low salinity waterflooding is a modified technique of waterflooding. The low ionic strength brine is injected into reservoir to create Multi-Ion Exchange (MIE) mechanism at rock surface and alteration of rock wettability to more favorable conditions for oil production is expected. A few studies have been performed on carbonate rocks and it is observed that oil recovery mechanism is occurred through collaboration of Potential Determining Ions (PDI) which consist of calcium ion $\left(\mathrm{Ca}^{2+}\right)$, magnesium ion $\left(\mathrm{Mg}^{2+}\right)$ and sulfate ion $\left(\mathrm{SO}_{4}{ }^{2-}\right)$ [1]. Sulfate ion, possessing two negative charges, in injected water will compete with adsorbed organic acid in oil to adhere onto positively charged carbonate surface, causing less attraction force between oil and carbonate surface. At the same time, calcium and magnesium ions attract polar compounds in oil to form calcium or magnesium carboxylate complexes [5].

Nevertheless, appropriate number of calcium and magnesium ions should be presented in brine phase as reduction of these two ions also favors dissolution mechanism of calcium and magnesium (in case of dolomite formation) from rock surface to brine solution. It is also observed that dissolution of calcium ion results in increment of $\mathrm{pH}$ value due to accumulation of hydroxide ion $(\mathrm{OH}-)$ and as a consequence, carbonate surface may change its charge from positive to negative once the $\mathrm{pH}$ value rises beyond 9 which is point of zero charge of carbonate surface. When oil is liberated from rock surface, wettability is altered from oilwet to a more water-wet direction and at the same time, oil recovery is increased. Fig. 1 illustrates oil recovery mechanisms by means of PDI in carbonate reservoirs.
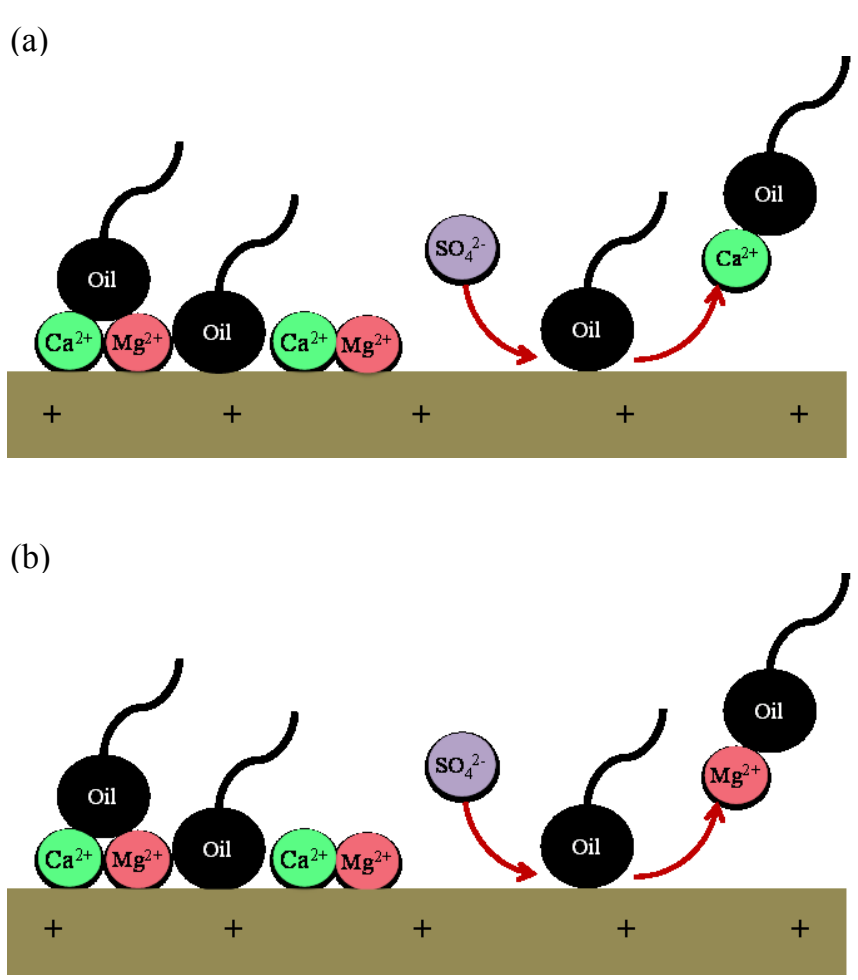

Fig. 1. Oil recovery mechanisms by means of collaboration between calcium ion, magnesium ion, and sulphate ion in carbonate reservoir, (a) Correlation between calcium ion and sulfate ion at normal temperature. (b) Correlation between magnesium ion and sulfate ion at high temperature.

Under reservoir conditions, formation brine, crude oil and rock surface are in equilibrium. Wettability is established from attachment of oil onto rock surface due to charge effect. Presences of different ions in formation brine therefore, can result in different strength of wettability and this can affect the effectiveness of several processes to enhance oil recovery including LSWF. In carbonate reservoir, total salinity as well as proportion of each ion can be varied. As divalent ions are found to determine effectiveness of LSWF, ranges of these two ions in formation brine are investigated in this study. From table I, calcium and magnesium ratio in carbonate formation is varied in the range of $3: 1$ to $15: 1$ and sulphate ion is mostly absent. Different ionic properties of calcium and magnesium ions such as ionic radius and ionic mobility may be differed from case to case as ratio of calcium to magnesium ion is changed and this could result in strength of wettability as well as amount of active ions during the LSWF.

\section{METHODOLOGY}

The experimental study is divided into two parts which are imbibition test and coreflood test. The formation brine compositions are varied in each test as an investigated parameter. 


\section{A. Determination of basic parameters and preparation of} brines

Outcrop Silurian dolomite core samples with permeability between $100-400 \mathrm{mD}$ and porosity between $0.16-0.18$ are used in this study. Formation brine is prepared to have total salinity of $160,000 \mathrm{ppm}$ which is obtained from the average total salinity of formation brine in carbonate formation around the world. Total concentration of divalent ion is fixed at $15,000 \mathrm{ppm}$. Seawater with total salinity of $35,000 \mathrm{ppm}$ is used to represent low salinity water.

\section{B. Performing of imbibition test to select appropriate ratios} of divalent ions in formation brine

Core samples with diameter of $3.8 \mathrm{~cm}$ and length of about $6.5 \mathrm{~cm}$ are saturated with formation brine with various calcium ion to magnesium ion ratios in the range of $1: 1,3: 1$, 10:1 and 15:1 (Table I) by using coreflood apparatus followed by saturating core samples with dodecane which represents crude oil. Then, all core samples are soaked in formation brines for imbibition test and weighted every 24 hours to collect mass data for calculation of fluid saturations. After the weight of core samples is constant, all core samples are switched to soak in seawater to perform LSWF. Samples with the largest improvement in terms of oil recovery factor are chosen for displacement by coreflood test.

TABLE I. COMPOSITION OF FORMATION BRINE AND SEAWATER AROUND THE WORLD

\begin{tabular}{|c|c|c|c|c|c|c|}
\hline \multirow{2}{*}{$\begin{array}{c}\text { Ionic } \\
\text { species } \\
(\mathbf{p p m})\end{array}$} & \multicolumn{2}{|c|}{ Reference [2] } & \multicolumn{2}{c|}{ Reference [3] } & \multicolumn{2}{c|}{ Reference [4] } \\
\cline { 2 - 7 } & $\boldsymbol{F W}$ & $\boldsymbol{S W}$ & $\boldsymbol{F W}$ & $\boldsymbol{S} \boldsymbol{W}$ & $\boldsymbol{F W}$ & $\boldsymbol{S} \boldsymbol{W}$ \\
\hline $\mathrm{Na}^{+}$ & 49933 & 13700 & 10350 & 23000 & 51820 & 10345 \\
\hline $\mathrm{Ca}^{+}$ & 14501 & 521 & 1160 & 520 & 15992 & 521 \\
\hline $\mathrm{Mg}^{2+}$ & 3248 & 1620 & 192 & 1080 & 1282 & 1094 \\
\hline $\mathrm{K}^{+}$ & 0 & 0 & 195 & 390 & 0 & 392 \\
\hline $\mathrm{Cl}^{-}$ & 111810 & 24468 & 18638 & 37985 & 111717 & 18719 \\
\hline $\mathrm{SO}_{4}{ }^{2-}$ & 234 & 3310 & 0 & 2304 & 0 & 2305 \\
\hline $\mathrm{HCO}_{3}{ }^{-}$ & 0 & 0 & 567 & 126 & 391 & 0 \\
\hline $\mathrm{TDS}^{2}$ & 179730 & 43619 & 62800 & 33390 & 181202 & 33375 \\
\hline
\end{tabular}

\section{Performing of coreflood test to study effects of formation} brine compositions to oil recovery performance

In this section, cases with improvement by means of LSWF from imbibition tests are selected to perform by using coreflood apparatus (fig. 2). Core samples used in step 2 are saturated with chosen formation brine followed by dodecane until residual oil saturation is attained. Saturated core samples are aged for 1 week and after that, core samples are flooded by formation brine to perform conventional waterflooding. Once amount of displaced oil is constant, seawater is injected to perform LSWF. Confining pressure of $2,000 \mathrm{psi}$ and temperature of $30^{\circ} \mathrm{C}$ are applied to the system, whereas injection rate is fixed at constant value of 0.5 $\mathrm{cm}^{3} / \mathrm{min}$.

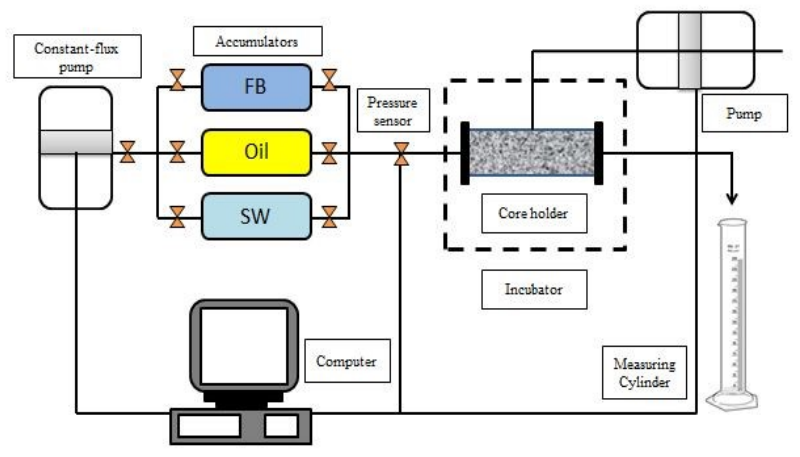

Fig. 2. Coreflooding system

\section{RESULTS AND DISCUSSION}

Results obtained from imbibition test are illustrated in terms of relationship between oil recovery factor and time in fig. 3. As water and oil are different in density, amount of oil that is displaced can be calculated from the mass balance of total fluid weight in core sample. As water imbibes into core, expelling oil out, weight of sample is increased due to higher density of water compared to oil. From the figure, it can be noticed that oil recovery factor by means of formation water itself is quite small in most case except one with the calcium to magnesium ratio in brine of $1: 1$. When samples are switched to soak in seawater which is at the 8th day where oil recovery factors of all cases are constant, it is even more obvious that the case with brine containing calcium ion to magnesium ion ratio of 1:1 obtains the highest improvement in terms of oil recovery. At the end of the test, oil recovery factor of $26.02 \%$ is obtained. From the figure it can also be observed that the higher amount of calcium ion in formation brine, oil is difficultly displaced by both formation brine itself as well as seawater which is low salinity water. This can explain behaviors of calcium ion and magnesium ion during

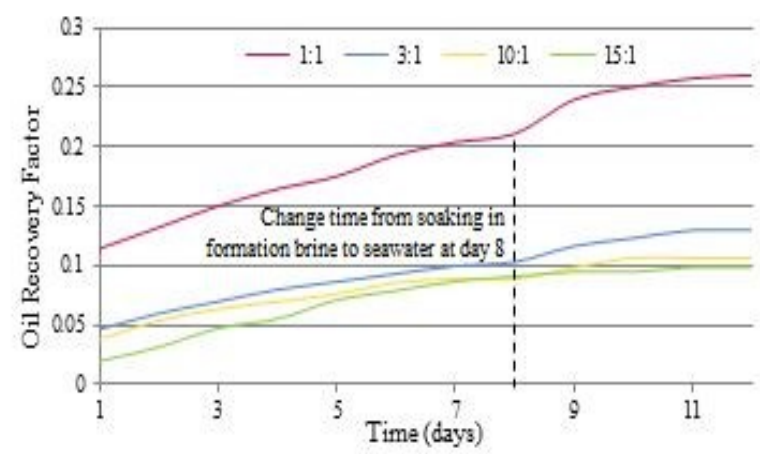

Fig. 3. Oil recovery factor from imbibition tests for formation brines with various ratios of calcium ion to magnesium ion as a function of time.

Presence of both calcium ion and magnesium ion is important for dolomite formation since dolomite composes of both ions inside its crystalline structure. Dissolution mechanism of both ions therefore depends on quantity of 
them inside enclosed water. Considering calcium ion first, calcium is one of the active ion in oil recovery mechanism by means of LSWF. Presence of calcium ion in injected water will form calcium carboxylate complex with adsorbed carboxylic acid. Attraction between oil and carbonate surface is then lessened and oil can be easily liberated. However, liberation of oil might require dissolution of calcium ion at the surface. This mechanism can occur rapidly when amount of calcium ion in injected brine is small. Therefore, dissolution can occur to adjust the equilibrium. When formation water contains high concentration of calcium ion, these ions from connate water will diffuse to injected water and increase total amount of calcium ion in the environment quickly. Even though calcium carboxylate complex can be formed, dissolution of calcium ion is obstructed and oil cannot be liberated.

Considering effects of magnesium ion, it is usually found that amount of magnesium ion in formation brine is less than calcium ion. Magnesium ion is also part of dolomite formation and similar to calcium ion, dissolution of magnesium ion may occur when low salinity water is injected. Nevertheless, magnesium ion cannot form magnesium carboxylate complex at low temperature and presence of magnesium ion in the environment does not cause much effect in oil recovery mechanism. Higher portion of magnesium ion can still prevent the dissolution mechanism of magnesium in formation. However, when portion of magnesium is high, portion of calcium ion is small and this favors dissolution of calcium ion in rock formation and amount of calcium ion in injected brine is adequate to form calcium carboxylate complex.

From imbibition tests, there are two cases where effects of LSWF is observed which are ratios of calcium ion to magnesium ion in formation brine of $1: 1$ and $3: 1$ and these two cases are chosen to perform coreflood test. Results are illustrated in fig. 4 and they still follow similar trend as obtained from imbibition test.

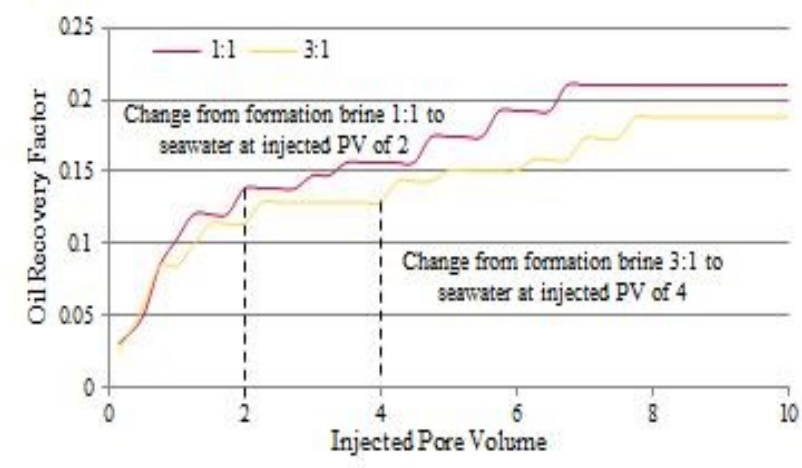

Fig. 4. Oil recovery factor from coreflood test with formation brine with various ratios of calcium ion to magnesium ion as a function of injected PV.

\section{CONCLUSIONS}

From this study, it can be concluded that high calcium ion concentration in formation brine is not favorable condition for LSWF in carbonate formation. As high calcium ion concentration in connate water can diffuse to injected water, environment with high amount of calcium ion starts to obstruct rock dissolution which is one of the favoring mechanisms for oil production. Amount of magnesium ion does affect the effectiveness of LSWF. Even though dissolution of magnesium ion may be obstructed from its high concentration, calcium carboxylate complex can be formed from adequate amount of calcium ion.

\section{ACKNOWLEDGMENT}

The authors would like to thank Chevron Thailand Exploration and Production, Ltd. for financial support of this study.

\section{REFERENCES}

[1] T. Austad, S. Strand, M.V. Madland, T. Puntervold, and R.I. Korsnes, "Seawater in chalk: an EOR and compaction fluid," in press

[2] S. Chandrasekhar and K.K. Mohanty, "Wettability alterations with brine composition in high temperature carbonate reservoirs," in press.

[3] S.J. Fathi, T. Austad, and S. Strand, "Smart Water as a wettability modifier in chalk: the effect of salinity and ionic composition," Vol. 24, Energy Fuels, 2010, , pp. 2514-2519.

[4] R. Gupta, P.G.J. Smith, L. Hu, T.W. Willingham, M.L. Cascio, J.J. Shyeh, and C.R. Harris [2011] "Enhanced waterflood for middle east carbonate cores - Impact of injection water composition," In press.

[5] P. Zhang, M.T. Tweheyo, and T. Austad, "Wettability alteration and improved oil recovery by spontaneous imbibition of seawater into chalk: Impact of the potential determining ions $\mathrm{Ca}^{2+}, \mathrm{Mg}^{2+}$, and $\mathrm{SO}_{4}{ }^{2-}$," Vol. 301, Colloids and Surfaces A: Physicochemical and engineering aspects, 2007, pp. 199-208. 